
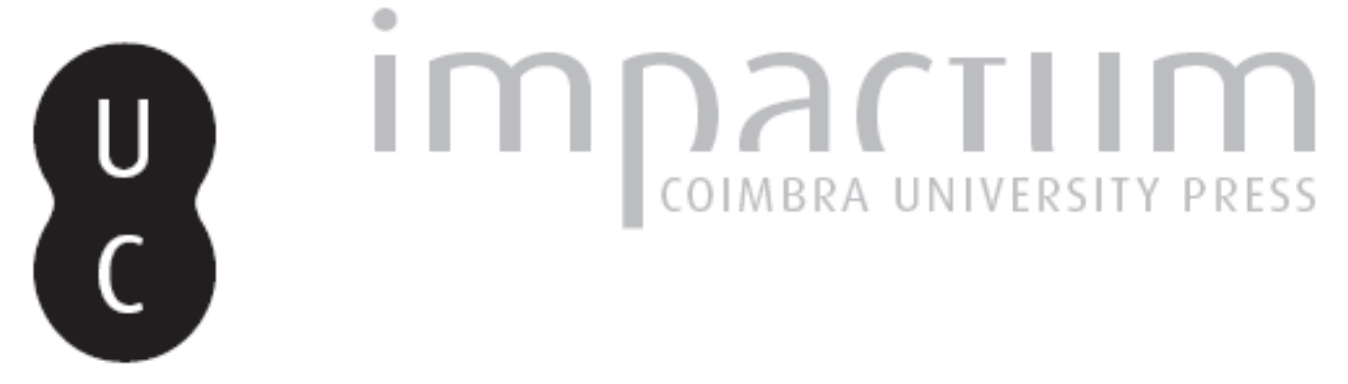

\title{
Gregório de Nissa e Tomás de Aquino: o surgimento da vida humana
}

\section{Autor(es): $\quad$ Camps, Maria da Conceição}

Publicado por: Imprensa da Universidade de Coimbra

URL persistente:

URl:http://hdl.handle.net/10316.2/42842

DOI:

DOI:http://dx.doi.org/10.14195/0872-0851_49_5

Accessed : $\quad$ 26-Apr-2023 00:46:50

A navegação consulta e descarregamento dos títulos inseridos nas Bibliotecas Digitais UC Digitalis, UC Pombalina e UC Impactum, pressupõem a aceitação plena e sem reservas dos Termos e Condições de Uso destas Bibliotecas Digitais, disponíveis em https://digitalis.uc.pt/pt-pt/termos.

Conforme exposto nos referidos Termos e Condições de Uso, o descarregamento de títulos de acesso restrito requer uma licença válida de autorização devendo o utilizador aceder ao(s) documento(s) a partir de um endereço de IP da instituição detentora da supramencionada licença.

Ao utilizador é apenas permitido o descarregamento para uso pessoal, pelo que o emprego do(s) título(s) descarregado(s) para outro fim, designadamente comercial, carece de autorização do respetivo autor ou editor da obra.

Na medida em que todas as obras da UC Digitalis se encontram protegidas pelo Código do Direito de Autor e Direitos Conexos e demais legislação aplicável, toda a cópia, parcial ou total, deste documento, nos casos em que é legalmente admitida, deverá conter ou fazer-se acompanhar por este aviso.

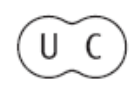




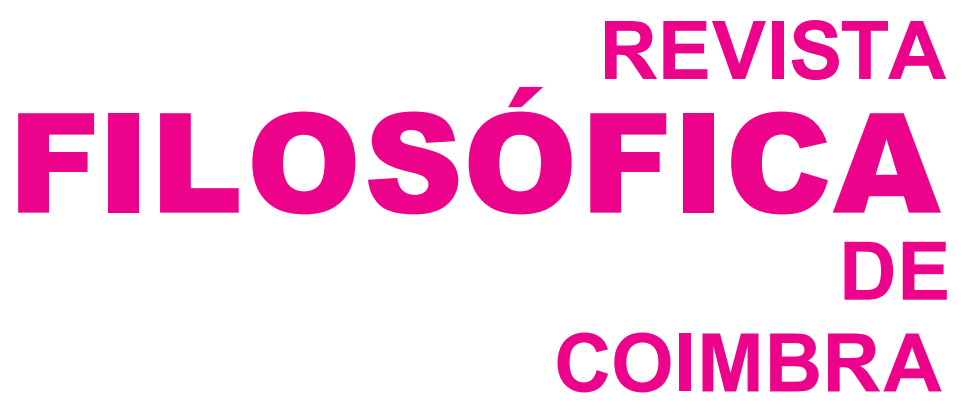

vol. 25 - número 49 - março 2016

vol. 25 - número 49 - março 2016

Fundação Eng. António de Almeida

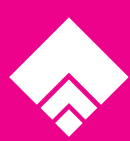




\title{
GREGÓRIO DE NISSA E TOMÁS DE AQUINO: O SURGIMENTO DA VIDA HUMANA
}

\author{
GREGORY OF NYSSA AND THOMAS AQUINAS,
} ON THE EMERGENCE OF HUMAN LIFE

MARIA DA CONCEIÇÃO CAMPS*

Resumo: Gregório de Nissa (335-394) e Tomás de Aquino (1225-1274) são lídimos representantes de duas correntes doutrinais cristãs relativas ao momento do surgimento da vida humana que têm enformado o pensamento ocidental. Este artigo propõe-se explicá-las, cotejá-las e perceber em que medida elas continuam presentes nos debates contemporâneos acerca do estatuto do embrião e da vida intrauterina. lei.

Palavras-chave: Gregório de Nissa, Tomás de Aquino, vida humana, embrião,

\begin{abstract}
Gregory of Nyssa (335-394) and Thomas Aquinas (1225-1274) are two major representatives of the Christian doctrines related to the moment of the emergence of human life, which have shaped Western thought. This article aims to explain and to compare them in order to understand how they are still influential in contemporary conceptions on the status of the embryo and intrauterine life.
\end{abstract}

Keywords: Gregory of Nyssa, Thomas Aquinas, human life, embryo, law.
Résumé: Grégoire de Nysse (335-394) et Thomas d'Aquin (1225-1274) sont les deux plus grands représentants des doctrines chrétiennes concernant le moment de la création de la vie humaine qui ont façonné la pensée occidental. Cet article veut expliquer, rassembler et rendre compte de la façon dans laquelle leurs théories sont encore présentes dans les conceptions contemporaines sur le statut de l'embryon et la vie intrautérine.

Mots-clefs: Grégoire de Nysse, Thomas d'Aquin, vie humaine, embryon, loi.

* Doutora em Filosofia, U.I.\&D., LIF - Universidade de Coimbra; email: camps. maria@gmail.com 


\section{NOTA PREAMBULAR}

A vida, a natureza e o cosmos foram desde sempre alimento privilegiado do pensamento filosófico. Seja qual for o prisma por que se olhe o homem e o universo deparamo-nos invariavelmente com o mistério indecifrável das causas, dos fins últimos, do sentido da vida em todas as suas etapas e variantes biológicas, psicológicas, espirituais. Esse absoluto mistério submerge o homem, empurrando-o para Deus, seja para $\mathrm{O}$ acolher, seja para $\mathrm{O}$ negar, seja para $\mathrm{O}$ tentar ignorar. $\mathrm{O}$ mistério das origens e do sentido, não obstante, permanece.

É este o cenário em que decorre a vida humana, uma existência como que desentranhada de um nada paradoxal, um interlúdio no seio de um enigma, uma pausa entre duas interrogações. O que houve antes de mim? O que haverá depois? No agora do Tempo a pergunta devém sem resposta. Antes de mim existia um mundo que já estava feito antes da minha chegada, mundo esse que permanecerá depois de mim. $\mathrm{O}$ antes e o depois da pergunta pessoal emolduram a unicidade de cada Homem.

A pluralidade de explicações surgidas sobre o princípio e o fim da vida humana geraram, desde sempre, controvérsias e dissensões entre partidários de várias correntes filosóficas, designadamente entre os pensadores da Cristandade. ${ }^{1}$ Quando tem início a vida humana? Será a matéria da conceção já uma pessoa? Será dotada de alma? Em caso afirmativo, de que tipo de alma? Em que momento se efetua a união da alma com o corpo? Haverá, de facto, um momento preciso? Donde vem e o que é a alma? Pré-existirá ao corpo? Será que o corpo the é anterior ou serão criados simultaneamente? Será a alma material ou imaterial?

Se, hoje, uma parte destas questões encontram resposta na ciência, designadamente no campo da investigação genética, da procriação medicamente assistida, do aborto e da contraceção, onde o estatuto do embrião é amplamente debatido, dando origem a importantes controvérsias no domínio da bioética, no período medieval a discussão sobre a animação do embrião teve sobretudo como objetivo responder a questões do foro religioso, como as relacionadas com a problemática da ressurreição da carne, o papel do corpo no desígnio do Criador, a transmissão, ou não, do pecado original através da geração e, na própria Cristologia, com o intuito de averiguar a possível existência de um hiato entre a encarnação do Verbo e a conceção de Cristo.

1 Não obstante, as discussões acerca desta matéria também apaixonaram desde cedo os pensadores da Antiguidade. Sobre este assunto vide Richard Sorabji, Animal Minds \& Human Morals, The Origins of the Western Debate (Ithaca, New York: Cornell University Press, 1995), 100-104. 
Visava-se também combater posições contrárias à Fé e alguns erros doutrinários, como sejam a crença na metempsicose, as heresias de Gnósticos, de Maniqueus e de Priscilianistas, as posições dos Luciferianos, de Apolinário e de Tertuliano, afirmando que a alma se reproduzia a partir do sémen e, também, as daqueles que consideravam que as almas intelectivas tinham sido criadas pelas Inteligências, não por Deus, doutrina que esteve na origem da heresia dos Messalianos.

\section{O EMBRIÃO}

A definição de embrião também tem sido alvo de acesa polémica e, consequentemente, também o seu estatuto. Partimos do princípio consensualmente aceite, hoje, de que o embrião é um ser vivo pertencente à espécie humana, composto de uma estrutura multicelular portadora de um genoma humano, isto é, dotado de um conjunto de genes único e irrepetível. Subsiste a polémica, em que não entraremos aqui, sobre se deverá ser considerado uma pessoa, uma vida humana, uma pessoa potencial ou um agregado celular em processo de hominização.O genoma humano tem capacidade para interagir com a natureza exterior e, a partir desta dinâmica, originar um ser humano. $\mathrm{O}$ embrião integra em si um projeto humano que se manifesta no tempo, adotando formas sucessivas e distintas, comandadas pelos genes organizadores. O problema atual mais suscitado pela bioética prende-se com o facto de ser possível, graças ao desenvolvimento da técnica, a fecundação fora do corpo da mulher e, portanto, a existência de embriões que sobrevivendo fora do seio materno, são suscetíveis de utilizações diversificadas. Emerge a polémica quanto à licitude da sua utilização para fins múltiplos, como sejam a experimentação científica, a clonagem, o congelamento de embriões vivos tendo em vista utilizações futuras. ${ }^{2} \mathrm{O}$ embrião humano é o ser vivo resultante da fecundação do ovócito pelo espermatozóide, que se desenvolve até à décima semana de amenorreia, ou seja, que na oitava semana do seu desenvolvimento intrauterino devém feto. A ciência atual permite-nos assinalar este momento como o fim da organogénese. Esta etapa é o marco delimitador a partir do qual o embrião acolhe o nome de feto e o correspondente estatuto ético-jurídico.

2 Vide a respeito deste assunto, de entre outros, os seguintes pertinentes Pareceres e diplomas legais, como sejam: o Relatório-Parecer sobre experimentação no embrião Conselho Nacional de Ética para as Ciências da Vida, 15/CNECV/ 95, designadamente os pontos 4 e 11; a Declaração Universal do Genoma Humano e dos Direitos Humanos da Unesco de 11/11/ 1997 da Conferência Geral da Unesco; e o Relatório da CNECV sobre Procriação Medicamente Assistida, de julho de 2004, www.cnecv.gov.pt. (em 13 de janeiro de 2015). 
A Idade Média desconhecia ao certo quando se completava a organogénese, sendo normalmente seguida a posição de Aristóteles. À luz do conhecimento que então os autores possuíam, o embrião era o produto da conceção até aos quarenta ou oitenta dias de vida intrauterina aproximadamente, consoante o nascituro fosse macho ou fêmea, respetivamente. ${ }^{3}$

Deve sublinhar-se que, hoje como ontem, a etapa da organogénese continua a ser considerada fundamental para a viabilidade do projeto humano, ou seja, para um nascimento bem sucedido. Por isso ela é especialmente registada, concedendo a ciência um estatuto diferente ao feto e ao embrião. Resta então perguntar se o embrião antes da organogénese deve ser considerado como um ser humano, ou não. Evitamos deliberadamente a discussão recorrente sobre a diferença entre vida humana e pessoa humana, preferindo a designação mais genérica de natureza humana, na esteira da terminologia adotada no Parecer do Conselho Nacional de Ética para as Ciências da Vida, onde se considera a natureza humana do embrião e, consequentemente, que «se deve interditar qualquer experimentação sistemática e planeada no embrião pese embora o custo científico de tal proibição». ${ }^{4}$

\section{ANIMAÇÃO DIFERIDA E ANIMAÇÃO SIMULTÂNEA}

\section{II.1. Animação diferida}

Até às investigações científicas modernas, subsistiram duas posições relativas à problemática sobre o momento em que a alma e o corpo se juntam para viabilizar o projeto humano. Referimo-nos às teses da «animação diferida» e da «animação simultânea». A primeira parte do princípio de que a alma (intelectiva) é criada por Deus e infundida no feto após a conclusão da organogénese. A segunda afirma que a animação se dá por ocasião da fecundação, isto é, desde o primeiro momento da existência do embrião.

A primeira posição foi mais comum entre os autores latinos, com exceção de Tertuliano. A segunda foi a preferida dos autores gregos, com exceção de Teodoreto de Ciro. De entre os seguidores da animação diferida ressalta Tomás de Aquino como o seu mais representativo defensor, enquanto Gregório de Nissa é, de algum modo, o mais proeminente partidário da segunda. De passagem, faremos uma breve alusão a Tertuliano, aquando da discussão da animação simultânea.

Tomás de Aquino radica compreensivelmente em Aristóteles a sua posição, reconduzindo à unidade a relação alma corpo ao opor-se ao dualismo

\footnotetext{
3 Aristóteles, História dos Animais, 583b.

4 Parecer sobre experimentação no embrião - 15/ CNECV/ 95, ponto 4 .
} 
platónico. Tal como Aristóteles, refere que a alma é forma e enteléquia de um corpo vivo, orgânico, que tem a vida em potência. ${ }^{5} \mathrm{O}$ embrião possui alma vegetativa porque, embora não se reproduza, cresce e alimenta-se. No entanto, só alcançará o estatuto de ser humano, uma vez perfeitos os órgãos adequados ao desempenho das funções vitais. Considera que a alma intelectiva vem de fora, sendo criada por Deus e junta ao corpo uma vez concluída a organogénese ${ }^{6}$. No seu início o embrião tem uma alma apenas sensitiva que é substituída por outra mais perfeita, ao mesmo tempo sensitiva e intelectiva. ${ }^{7}$ A alma intelectiva é a única forma substancial do Homem ${ }^{8}$. Ou seja, à luz desta teoria, o embrião não é um ser humano, só ganhando tal estatuto quando devém feto, momento em que recebe a alma intelectiva. No projeto humano intervêm geração e criação, sucedendo-se no tempo. Se o embrião perecer antes da intervenção criadora não chegará a alcançar a humanidade. Esta posição teve consequências práticas, designadamente na adoção de determinadas posições doutrinárias ao longo dos séculos, como é o caso da adotada no "Comentário» ao De anima do "Cursus Comimbricensis». ${ }^{9}$

A etapa da organogénese e a ideia de que esta constitui um marco delimitador ou, diríamos, probatório da existência do ser humano, encontra-se subjacente à denominada cultura ocidental e judaico-cristã, enformando um conjunto de comportamentos, atitudes e crenças, nos mais diversos domínios, desde o religioso ao jurídico, passando pelo científico. Efetivamente, a interrupção voluntária da gravidez a pedido da mulher, do ponto de vista juridico tem em conta o estádio em que o feto é conformado, ou seja, a organogénese ${ }^{10}$. Sem dúvida que se encontra subjacente a ideia de que a pessoa humana de algum modo, pelo menos na aparência, começa ali.

A tal preconceito não é estranha uma outra superstição bem presente na sociedade europeia, pelo menos até ao século XIX. Referimo-nos à crença

5 Tomás de Aquino, In Aristotelis librum de Anima Commentarium II 1, § 230-232.

${ }^{6}$ Aquino, Su. theol. Ia , q. 118, a. 2: "Manifestum est autem quod principium intellectivum in homine est principium transcendens materiam: habet enim operationem in qua non communicat corpus. Et ideo impossibile est quod virtus quae est in semine, sit productiva intellectivi principii. (...) Similiter etiam anima intellectiva (...) cum sit immaterialis substantia, non potest causari per generationem, sed solum per creationem a Deo."

7 Aquino, Su theol. I', q. 76, a. 3, ad 3um: “... dicendum quod prius embryo habet animam quae est sensitiva tantum; qua abiecta, advenit perfectior anima, quae est simul sensitiva et intellectiva..."

8 Aquino, Su theol. I ${ }^{\text {a }}$, q. 76, a. 4.

9 Comentarii Colegii Conimbricensis, In três libros de Anima Aristotelis Stagiritae, Conimbricae 1598, 1.2, q.4, a.2. Sobre este assunto vide Maria da Conceição Camps, "A problemática do surgimento da vida humana no Comentário Jesuíta conimbricense ao «De Anima» de Aristóteles", Revista Filosófica de Coimbra, 19 (2010), 187-198.

10 Vide Lei no 16/ 2007 de 17 de abril, para o caso português. 
generalizada de que a mulher poderia dar à luz seres não humanos, fruto de ligações com demónios, incubus e outros entes aberrantes. A figura humana, funcionaria, assim, como uma espécie de certificado de humanidade do próprio produto da conceção. Tal crença chegou a integrar a legislação nacional portuguesa até há bem poucos anos. O nosso primeiro Código Civil, o denominado Código de Seabra (por sua vez inspirado no Código Napoleónico) que vigorou desde 1867 até à entrada em vigor do atual Código Civil Português em 1966, prescrevia no seu artigo $110^{\circ}$ :

«Só é tido por filho, para efeitos legais, aquele de quem se prove que nasceu com vida e com figura humana»,

fazendo por sua vez depender do artigo $1^{\circ}$ do mesmo articulado, a atribuição da personalidade jurídica apenas às pessoas. Desconhecemos ao certo quantos casos existiram, se é que alguns houve ou vieram a público, em que a personalidade jurídica não foi atribuída ao recém-nascido, nem instituído o poder paternal, em virtude do mesmo não aparentar forma humana, mas, para todos os efeitos, não deixa de ser significativo que tal ideia tivesse tido consagração legal. A perfeição dos órgãos, para além da aptidão para estar vivo, era a prova de que aquela vida acabada de vir à luz era humana, de que aquele ser era um homem, que tinha alma e, portanto, seria suscetível de possuir personalidade jurídica, em ordem a ser tratado como pessoa e como cidadão.

\section{II.2. Animação simultânea}

Enquanto na teoria anterior está pressuposta a pré-existência do corpo em relação à alma (referimo-nos à alma intelectiva), a teoria da animação simultânea assenta no princípio da criação simultânea do corpo e da alma. Gregório de Nissa é o grande representante desta corrente, marcando a tradição grega, ao afirmar a coexistência, desde a origem, da alma e do corpo. No entanto, também o latino Tertuliano no seu livro De Anima ${ }^{11}$ tal afirmara, procurando combater as doutrinas que consideravam que alma teria a sua origem na criação angélica, bem como as que defendiam a transmigração. Não podemos deixar de referir, ainda que brevemente, a posição deste autor, dada a sua importância nesta sede.

Para Tertuliano, a alma e o corpo coexistem desde a conceção, afirmando que o que se separa ao mesmo tempo com a morte, se junta ao mesmo tempo com a vida. Defende a existência de uma semente da alma e de uma semente do corpo. A alma e o corpo juntam-se no ato sexual. O coito resulta da

11 Referimos aqui em particular Tertuliano, De Anima, cc. XXIII a XXXVII (PL 2). 
cooperação da alma e do corpo. A criação de Adão originou dois elementos separados, o barro e o sopro que constituíram o ser humano. As duas substâncias, fundidas numa única, misturaram também as sementes e legaram a forma à propagação da espécie. Deus criou em Adão todos os homens, dele descendendo toda a humanidade. Há uma única criação ${ }^{12}$. A humanidade, na sua totalidade deriva dessa criação primeira e está regulada por uma potência que é serva da vontade divina. O elemento alma propaga-se do mesmo modo que o elemento corpo. A noção de alma como corpo subtil facilita a adoção desta tese. $\mathrm{O}$ traducionismo de Tertuliano inspira-se na tradição estóica que afirmava a existência do sopro vital a partir da semente, ainda que, para os estóicos, apenas se transformasse em alma no momento do nascimento da criança. Tertuliano afirma a unicidade da alma e a sua presença desde a semente. A alma é transmitida durante a união sexual, pelo sémen, no momento do clímax masculino. Não podemos deixar de referir a interessante e a todos os títulos sugestiva, passagem que sobre o assunto descreve: ${ }^{13}$

«Na grandiosa função dos sexos que une o homem e a mulher, digo, nesta comum união carnal, sabemos que a alma e a carne desempenham simultaneamente a sua função: a alma o desejo, a carne os atos, a alma o impulso, a carne a realização. É então que o empenho conjugado de uma e de outra sacode o homem todo e que a semente do homem, todo inteiro, se derrama como uma espuma, contendo da sua substância corporal, a substância fluida e da sua substância espiritual, o calor. (...) Finalmente, prefiro correr o risco de ferir o pudor do que o de enfraquecer a minha argumentação, no frémito do derradeiro estádio do prazer, em que se procede à ejaculação do humor genital, não sentimos nós sair também qualquer coisa da nossa alma, a tal ponto desfalecemos e ficamos privados de força, perdendo mesmo a visão por um breve instante? Tal é a semente da alma, procedendo da destilação da alma, tal como o humor é a semente do corpo, extraída da evacuação da carne.»

Mas Gregório de Nissa foi, sem dúvida, o lídimo representante da animação imediata e, a nosso ver, aquele cuja teoria mais se aproxima das posições científicas atuais, no que respeita ao desenvolvimento intrauterino do ser hu-

12 Gn. 1, 28.

13 Tertuliano, De Anima, c. XXVII (PL 2, 695b) "In hoc itaque sollemni sexuum officio quod marem ac feminam miscet, in concubitu dico communi, scimus et animam et carnem simul fungi, animam concupiscentia, carnem opera, animam instinctu, carnem actu. Vnico igitur impetu utriusque toto homine concusso despumatur semen totius hominis habens ex corporali substantia humorem, ex animali calorem.(...) Denique ut adhuc uerecundia magis pericliter quam probatione, in illo ipso uoluptatis ultimae aestu quo genitale uinis expellitur, nonne aliquid de anima quoque sentimus exire atque adeo marcescimus et deuigescimus cum lucis detrimento? Hoc erit semen animale, protinus ex animae destillatione, sicut et uirus illud corporale semen ex carnis defaecatione." 
mano. Defende a criação simultânea da alma e do corpo no momento da conceção e a unidade da alma. ${ }^{14}$ Tal como Tertuliano considera que em Adão, Deus criou a humanidade, ainda que distinga a criação primeira da natureza humana, da criação individual de cada homem. No que respeita à criação de cada indivíduo não deve ser considerada a criação da alma ou do corpo, um antes do outro, pois isso levaria ao conflito do homem consigo mesmo. ${ }^{15}$

Segundo este autor, nem a alma existe antes do corpo, nem o corpo existe sem a alma, mas há para os dois, uma origem única. ${ }^{16}$

Todo o ser, alma e corpo, está contido no produto da conceção que encerra, em potência, todo o homem que há de vir ao mundo e nele crescer, desenvolver-se e morrer, possuindo um dinamismo interno que comanda aquela sucessão de estádios. A alma é única.

«Ninguém duvida que o futuro ser humano não contém os grandes traços distintivos da diferenciação em membros e vísceras e não necessita de uma potência estranha, já que a potência a ele inerente transporta naturalmente esta transformação através da atividade que ela possui; podemos raciocinar do mesmo modo no que respeita à alma. Mesmo que ela não se manifeste a olhos vistos por certas atividades, ela não está menos presente. De facto, a configuração do homem que há de surgir existe já em potência, mas a alma está ainda escondida já que não pode manifestar-se a não ser de acordo com a ordem necessária. Então, ela está presente mas invisível, ela não aparecerá senão graças ao exercício da sua atividade natural, ao acompanhar o desenvolvimento do corpo.» ${ }^{17}$

Gregório de Nissa considera que apenas o homem é dotado de alma. Os restantes seres vivos são portadores de uma energia vital que só poderá ser chamada alma, por analogia. Apenas a alma humana, ainda que escondida, ou seja, ainda que não manifestada, no seu estado embrionário, é suscetível de devir intelectiva. Ocorre uma espécie de desenvolvimento progressivo. ${ }^{18}$

14 Gregório de Nissa, De hominis opificio (PG 44, 233d, 236 b).

15 Gregório, De hominis, c. XXIX (PG 44, 233d).

16 Gregório, De hominis, c. XXIX (PG 44, 236b).

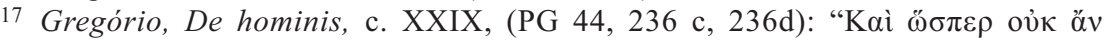

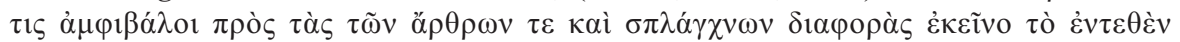

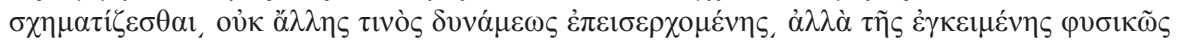

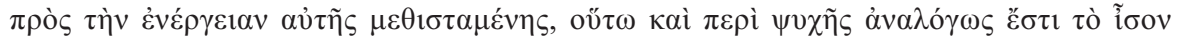

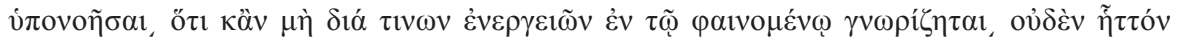

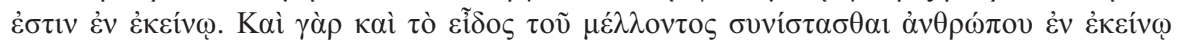

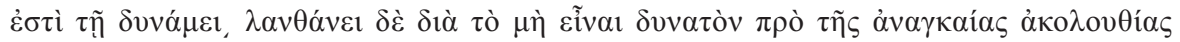

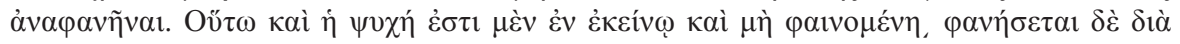

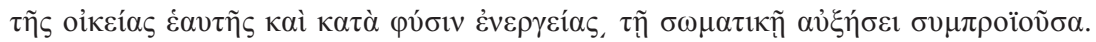

18 Gregório, De hominis, c. XXIX (PG 44, 237b). 
«Descobrimos nos seres vivos três faculdades distintas. A primeira, nutritiva, não tem sensação; a segunda, nutritiva e sensitiva ao mesmo tempo, não tem atividade racional; enfim, a última, racional e perfeita, difunde-se através das outras, de tal modo que está presente em todas e no espírito, na sua parte superior. No entanto não devemos concluir que o composto humano é formado de uma mistura de três almas. Na realidade, a alma, na sua verdade e perfeição, é única por natureza, sendo ao mesmo tempo espiritual e sem matéria e, através dos sentidos, misturada com a natureza material. ${ }^{19}$

Tal como a alma tem a sua perfeição naquilo que é inteligente e dotado de razão, tudo aquilo que não realiza esta qualidade pode receber por semelhança o nome de alma, mas não o é realmente. Trata-se, então, de qualquer energia vital chamada alma por semelhança.» ${ }^{20}$

Não podemos deixar de registar, aqui, a espantosa semelhança entre a descrição que Gregório de Nissa faz do desenvolvimento embrionário e as recentes pesquisas científicas que explicam o desenvolvimento do zigoto. A vida humana existe enquanto projeto organizado desde o primeiro momento. A formação do ser humano, do homem particular, como que recapitula ${ }^{21}$ a criação dos seres cósmicos, atingindo o seu ponto mais alto, já que é dotado de razão, o que o torna o único ser dotado de alma. A alma, presente desde o início no embrião, contém em potência o ulterior desenvolvimento do projeto humano, projeto temporalizado e dotado de um dinamismo próprio. De realçar a perceção da organização embrionária, não enfatizando a etapa da organogénese, tão querida a Aristóteles e a Tomás de Aquino.

\section{CONCLUSÃO}

Sem dúvida que o estatuto do embrião difere sobremaneira nos dois autores. Para Tomás de Aquino o embrião será, quando muito, uma vida humana

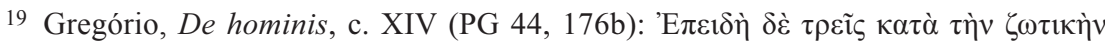

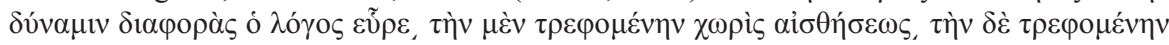

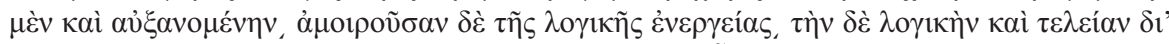

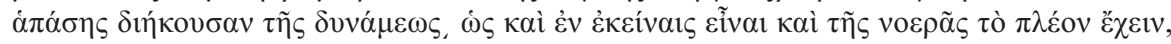

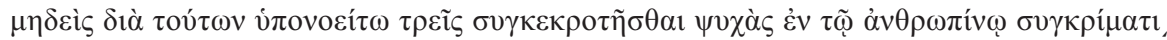

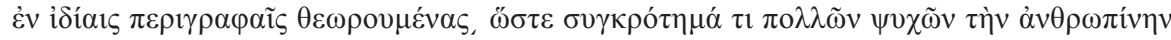

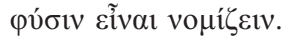

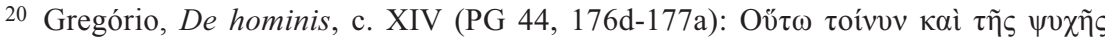

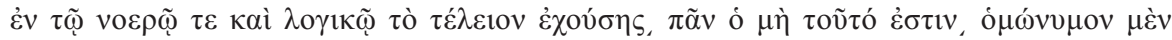

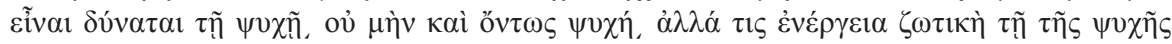

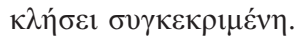

21 Maria Cândida da Costa Reis Monteiro Pacheco, S. Gregório de Nissa, Criação e Tempo (Braga: Publicações da Faculdade de Filosofia, 1983), 146. 
em potência, dependendo do processo de criação divina e consequentemente, da atribuição da alma intelectiva para alcançar o estádio da humanidade. Ou seja, em caso de morte antes da organogénese, o embrião não chegaria a ser considerado humano, subsistindo, então, a dificuldade na atribuição de um estatuto ontológico, já que a alma intelectiva é, para Tomás, a única forma substancial. A partir da descrição levada a cabo da formação sucessiva, é evidente a presença da geração e da criação num mesmo processo, num entrosamento difícil de situar no tempo e no lugar.

Persiste uma manifesta dificuldade subjacente à posição doutrinária que define a alma intelectiva como a única forma substancial subsistente do homem e o consequente hiato existente entre o momento da conceção e o surgimento do ser humano. Conclui-se que a verdadeira substancialidade do ser humano provém da intervenção criadora, divina, através da incorporação da alma racional, isto é, no momento em que o processo de geração é como que finalizado dando lugar a um outro, de natureza superior, transcendente. No entanto, o terminus da geração coincide com a perfeição dos órgãos corpóreos, fator essencial para a receção da alma intelectiva. Restará perguntar que ser gerado é este que ainda não é homem, mas não é apenas animal nem planta. A esta pergunta não é dada resposta satisfatória, mas é evidente que tal ser surge, sobretudo, como sujeito de um processo, de um dinamismo em que é definido, por tentativas, negativamente, pelo que ainda não é, mais do que por aquilo que efetivamente é. Figura como sujeito de um processo preparatório e adequado ao projeto da criação divina da alma racional. Nele, a perfeição do corpo é guardiã da alma racional e, uma vez incorporada esta, ela mesma absorve o que até ali ainda não era o Homem, integrando-o num todo indestrutível, pela incorporação da forma substancial subsistente, da alma intelectiva. Neste sentido, todo o percurso desde a fecundação até à incorporação da alma intelectiva e desta até ao nascimento propriamente dito, é como que um ato único, diferido no tempo, já que obedece a uma mesma finalidade.

Sem dúvida que a simultaneidade da alma e do corpo proposta por Gregório de Nissa, presentes desde o primeiro momento da vida humana, aliada ao princípio da unicidade da alma, nos causa menores dificuldades de perceção nos tempos hodiernos. Se juntarmos o facto do autor considerar o ser humano como o único ser criado por Deus, possuidor de alma no verdadeiro sentido do termo, tal ainda se tornará mais claro, a nosso ver. Em todo o caso, é bom realçar o que acima afirmámos, ou seja, que de algum modo, subsiste na nossa cultura, nos mais diversos planos, de forma mais ou menos explícita, estereotipada, a ideia de que a organogénese é um marco relevante, pelo menos do ponto de vista ético para o reconhecimento da viabilidade do ser humano. 
Cremos que a ética deve, nesta sede, atuar em permanente diálogo, mas com independência própria, face à ciência, não se escusando, como muitas vezes o tem feito, em pareceres científicos, em ordem a evitar uma posição menos cómoda. $\mathrm{O}$ facto de uma sociedade conhecer quando começa $\mathrm{e}$ quando acaba a vida humana de um ponto de vista estritamente biológico, não quer necessariamente dizer que deva valorar igualmente e com a mesma dignidade essa mesma vida em todas as etapas da sua existência, ou que a eventual diferenciação valorativa que venha a fazer, deva depender da maior ou menor precisão do conhecimento científico em cada momento. Aliás, não há memória de alguma vez o ter feito, de facto. Essa discussão virá inevitavelmente à colação, face à rapidez da evolução da ciência e, sobretudo, à velocidade do desenvolvimento tecnológico.

Comungamos da opinião de que é indispensável o comprometimento com o projeto humano na sua totalidade, com a sua dignidade pessoal, social e, diríamos, transcendental, tendo em conta que a pessoa é o escopo e o limite da atuação do próprio homem. Neste sentido, este fim e este limite deverão comandar os objetivos a atingir, as regras a seguir, mesmo na própria investigação científica, e não o contrário, à semelhança, aliás, do que fizeram com o empenhamento comprometido das suas vidas, no seu tempo, os autores que acabámos de abordar.

\section{REFERÊNCIAS BIBLIOGRÁFICAS:}

Gregório de Nissa. De opificio hominis, in J.-P. Migne, Patrologia Graeca, vol 44, Paris, 1860.

Tertuliano. De Anima, in J.-P. Migne, Patrologia Latina, vol. 2, Paris, 1844.

Sancti Thomae Aquinatis in Librum de Anima Commentarium. Cura ac studio P.F. Angeli M. Pirotta, Turim: Marietti Ed., 1959.

Tomás de Aquino. Suma teológica. Texto latino da Editio Leonina, São Paulo: Edições Loyola, 2003.

Comentarii Colegii Conimbricensis, In tres libros de Anima Aristotelis Stagiritae, Conimbricae 1598 [tradução in Comentários do Colégio Conimbricense da Companhia de Jesus Sobre os Três Livros Da Alma de Aristóteles Estagirita. Tradução do original latino por Maria da Conceição Camps, Lisboa: Edições Sílabo, 2010].

Pacheco, Maria Cândida da Costa Reis Monteiro. S. Gregório de Nissa, Criação e Tempo, Braga: Publicações da Faculdade de Filosofia, 1983.

Camps, Maria da Conceição. "A problemática do surgimento da vida humana no Comentário Jesuíta conimbricense ao «De Anima» de Aristóteles", Revista Filosófica de Coimbra, no 37 (2010), 187-198.

Sorabji, Richard. Animal Minds \& Human Morals, The Origins of the Western Debate, Ithaca, New York: Cornell University Press, 1995. 
(Página deixada propositadamente em branco.) 